\title{
Steady State Modeling and ANFIS Based Analysis of Doubly-Fed Induction Generator
}

\author{
Nadia A. Elsonbaty, Mohamed A. Enany, Ahmed M. Diab \\ * Department of Electrical power and machines, Faculty of Engineering, Zagazig University
}

\begin{abstract}
The paper presents a new technique for the steady state performance analysis of the DFIG using Adaptive Neuro-Fuzzy Inference System (ANFIS). First, a mathematical model of DFIG in an appropriate $d-q$ reference frame is established. The effect of the excitation voltage vector on the performance characteristics is illustrated to investigate simulations. A novel approach for the performance analysis of DFIG using ANFIS is employed for fast, accurate, and efficient methodology. The proposed ANFIS model has been trained off-line to predict the effect of excitation voltage magnitude, excitation voltage angle and speed on total output power of DFIG without overheating. The performance of the proposed scheme is investigated at different operating conditions. The simulation study indicates accuracy and effectiveness of the ANFIS based modeling of DFIG.

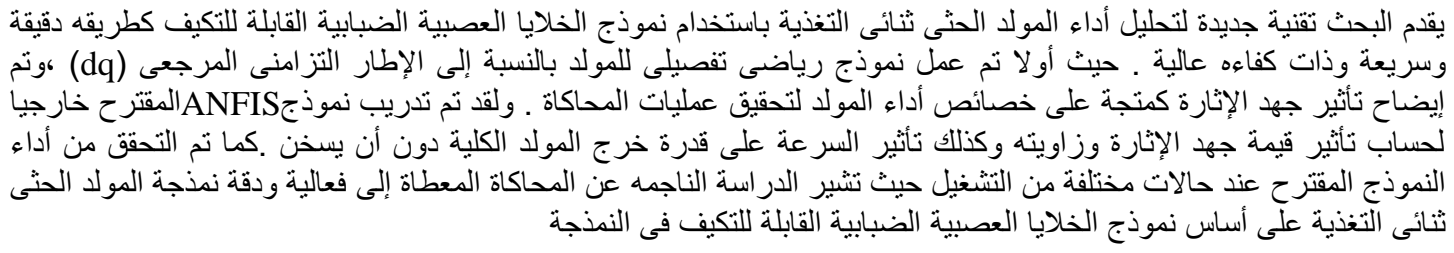

Keywords: Doubly-Fed Induction Generator, Adaptive Neuro-Fuzzy Inference System

\section{INTRODUCTION}

Renewable energy is playing a critical role in the establishment of an environmentally sustainable low carbon economy so that it has received much attention in the literature [1]-[4]. Among these renewable energy resources, it is found that the wind energy becomes the most economical one and most popular in the whole world. The most popular power generation systems with the wind turbines use a doubly fed induction generator (DFIG) with the back to back power electronics converter connected to the rotor. The DFIG have several advantages over the other generation systems as discussed in [5] .

The possibility of controlling the stator power by rotor voltage is the major advantage [6]. As the low power rotor involved of this machine, so DFIG is more attractive for the high power applications[7].

Also, variable speed operation and four quadrant active and reactive power capabilities, make the doubly fed induction generators (DFIGs) used in modern wind energy systems[8].

DFIG is considered as a wound rotor induction machine with three phase stator windings connected to the grid directly and its three phase rotor windings connected to the grid through back to back converter. The rotor of DFIG is mechanically connected to wind turbine through a drive train system, which may contain high and low speed shafts, bearings and gear box.

It can be controlled by the excitation voltage through the back-to-back converter.

Many researchers in [9-14] have been developed steady state model of DFIG-based on its equivalent circuit. Also evaluated the DFIG steady state characteristics, under varying system conditions. The adjustment of rotor excitation voltage and its angle has been proved its effect on the active and reactive power taking the system nonlinearity in to account. But such computations are quite difficult and require long time

Engineering Research Journal, Vol. 38, No.2, April 2015, PP: 117-125. 
with fatigued mathematical procedures. Artificial Neural Network (ANN) has been used to capture the characteristics of such complex system [15]

This paper presents a novel method to assessment of the DFIG steady state characteristics, using adaptive neuro-fuzzy inference system (ANFIS) which are widely used in many industrial applications [16]. ANFIS does not require the detailed mathematical procedures. After the ANFIS network implementation and comparing its result with the conventional method results, it is found that ANFIS network is robust and taking small time with more accurate.

\section{Steady State Model of DFIG}

The schematic representation of a DFIG driven by a mechanical turbine via a gearbox is shown in Fig.1.

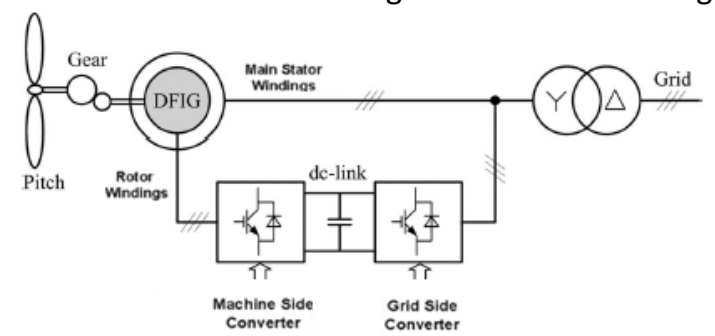

. DFIG configuration in wind power application.

The generalized equation of DFIG Using a D-Q theory in synchronous reference frame are given as follow [17];

The stator and rotor voltage equations are given below in frequency domain:

$$
\begin{gathered}
V_{s d q}=I_{s d q} R_{s}+J \omega_{s} \psi_{s d q} \\
V_{r d q}=I_{r d q} R_{r}+J \omega_{r} \psi_{r d q}
\end{gathered}
$$

Where ;

$$
\begin{aligned}
& \psi_{\text {sdq }}=L_{s} I_{\text {sdq }}+L_{m} I_{\text {rdq }} \\
& \psi_{\text {rdq }}=L_{r} I_{r d q}+L_{m} I_{\text {sdq }}
\end{aligned}
$$

According to (3) and (4) The stator and rotor current equations are given below in terms of stator and rotor fluxes.

$$
\begin{aligned}
& \mathrm{I}_{\mathrm{sdq}}=\frac{1}{\delta L_{S}} \psi_{\mathrm{sdq}}+\frac{-L_{m}}{\delta L_{s} L_{r}} \psi_{\mathrm{rdq}} \\
& \mathrm{I}_{\mathrm{rdq}}=\frac{-L_{m}}{\delta L_{S} L_{r}} \psi_{\mathrm{sdq}}+\frac{1}{\delta L_{r}} \psi_{\mathrm{rdq}} \\
& \text { Where; } \quad \delta=\frac{\left(L_{S} L_{r}\right)-\left(L_{m}^{2}\right)}{L_{s} L_{r}}
\end{aligned}
$$

According to (1), (2), (5) and (6) The stator and rotor voltage equations are given below in terms of stator and rotor fluxes.

$\mathrm{V}_{\mathrm{sdq}}=\left(J \omega_{s}+\frac{R_{S}}{\delta L_{S}}\right) \psi_{\mathrm{sdq}}+\frac{-L_{m} R_{S}}{\delta L_{s} L_{r}} \psi_{\mathrm{rdq}}$ $\mathrm{V}_{\mathrm{rdq}}=\left(J \omega_{r}+\frac{R_{r}}{\delta L_{r}}\right) \psi_{\mathrm{rdq}}+\frac{-L_{m} R_{r}}{\delta L_{s} L_{r}} \psi_{\mathrm{sdq}}$
Writing (7) and (8) in matrix form ; The stator and rotor flux equations are obtained below in terms of stator and rotor voltages fluxes by taking the inverse of previous matrix;

$$
\begin{aligned}
& \psi_{s d q}= \\
& \begin{array}{r}
\frac{1}{D n}\left[\left[\frac{1}{\delta * L_{r}}\left[\left(R_{r}+J \delta S X_{r}\right)\right] V_{s d q}\right]+\left[\frac{L_{m} R_{s}}{\delta L_{s} L_{r}} V_{r d q}\right]\right] \\
\psi_{r d q}= \\
\frac{1}{D n}\left[\left[\frac{1}{\delta * L_{s}}\left[\left(R_{s}+J \delta S X_{s}\right)\right] V_{r d q}\right]+\left[\frac{L_{m} R_{r}}{\delta L_{s} L_{r}} V_{s d q}\right]\right]
\end{array}
\end{aligned}
$$

Where;

$$
\begin{gathered}
\boldsymbol{D n}=\frac{\mathbf{1}}{\boldsymbol{\delta} \boldsymbol{L}_{\boldsymbol{s}} \boldsymbol{L}_{\boldsymbol{r}}}\left\{\left[\left(\boldsymbol{R}_{\boldsymbol{r}} \boldsymbol{R}_{\boldsymbol{s}}\right)-\boldsymbol{S}\left(\boldsymbol{X}_{\boldsymbol{s}} \boldsymbol{X}_{\boldsymbol{r}}-\boldsymbol{X}_{\boldsymbol{m}}^{\mathbf{2}}\right)\right]\right. \\
\left.+\boldsymbol{J}\left[\left(\boldsymbol{S} \boldsymbol{R}_{\boldsymbol{s}} \boldsymbol{X}_{\boldsymbol{r}}+\boldsymbol{R}_{\boldsymbol{r}} \boldsymbol{X}_{\boldsymbol{s}}\right)\right]\right\} \\
X_{S}=x_{s}+X_{m}, \quad X_{r}=x_{r}+X_{m}
\end{gathered}
$$

From Equations (9) and (10) in equations (5) an (6). The stator and rotor current equations are given below in terms of stator and rotor voltages.

$I_{s d q}$

$=\frac{\left[\left(R_{r}+J S X_{r}\right) V_{s d q}-J X_{m} V_{r d q}\right]}{\left\{\left[\left(R_{r} R_{s}\right)-S\left(X_{s} X_{r}-X_{m}^{2}\right)\right]+J\left[\left(S R_{s} X_{r}+R_{r} X_{s}\right)\right]\right\}}$

$I_{r d q}$

$=\frac{\left[\left(R_{s}+\mathrm{J} X_{s}\right) V_{r d q}-J S X_{m} V_{s d q}\right]}{\left[\left(R_{r} R_{s}\right)-S\left(X_{s} X_{r}-X_{m}^{2}\right)\right]+J\left[\left(S R_{s} X_{r}+R_{r} X_{s}\right)\right]}$

According to The generalized circuit Theory in synchronous reference frame, the steady state stator and rotor current can be expressed as follow:

$I_{S}$
$=\frac{\left[\left(R_{r}+J S X_{r}\right) V_{s}\left\lfloor 0-J X_{m} V_{r} \mid \alpha\right]\right.}{\left\{\left[\left(R_{r} R_{S}\right)-S\left(X_{S} X_{r}-X_{m}^{2}\right)\right]+J\left[\left(S R_{S} X_{r}+R_{r} X_{S}\right)\right]\right\}}$

$I_{r}$

$=\frac{\left[\left(R_{s}+J X_{s}\right) V_{r}\left\lfloor\alpha-J S X_{m} V_{s}\lfloor 0]\right.\right.}{\left[\left(R_{r} R_{S}\right)-S\left(X_{S} X_{r}-X_{m}^{2}\right)\right]+J\left[\left(S R_{S} X_{r}+R_{r} X_{S}\right)\right]}$

The instantaneous electromagnetic torque of a DFIG is given by [17];

$T=\frac{3}{2} P L_{m} \operatorname{Re}\left(\left(I_{s d} I_{r q}\right)-\left(I_{s q} I_{r d}\right)\right)$

According to equations (11) , (12) and the generalized 
circuit Theory in synchronous reference frame, the steady state Torque can be expressed as follow;

$T=\frac{3 P X_{m}^{2}}{\omega_{s} K(s)}\left\{\left(S R_{r} V_{s}^{2}\right)-\left(R_{s} V_{r}^{2}\right)-\frac{-V_{s} V_{r}}{X_{m}}(D r \sin \alpha-\right.$

$D i \cos \alpha)\}$ (16)

Where;

$\mathrm{K}(\mathrm{s})=\mathrm{D}(\mathrm{s}) . \mathrm{D}(\mathrm{s})^{*}$

$D(s)=\left[\left(R_{r} R_{s}\right)-S\left(X_{s} X_{r}-X_{m}^{2}\right)\right.$

$$
\left.+J\left[\left(S R_{S} X_{r}+R_{r} X_{S}\right)\right]\right]
$$

$D r=\left[\left(R_{r} R_{S}\right)-S\left(X_{S} X_{r}-X_{m}^{2}\right)\right]$

$D i=\left(S R_{s} X_{r}+R_{r} X_{S}\right)$

Also the steady state total power can be expressed as follow;

$P_{t}=\frac{3 P(1-s) X_{m}^{2}}{K(s)}\left\{\left(S R_{r} V_{s}^{2}\right)-\left(R_{s} V_{r}^{2}\right)+\frac{-V_{s} V_{r}}{X_{m}}(\operatorname{Dr} \sin \alpha-\right.$

$D i \cos \alpha)\}(17)$

From the above equation it is obvious that the power in the DFIM consists of three components;

1- First component is induction power, this power is positive or negative according to slip value.

$P_{i n 1}=\frac{3 P(1-s) X_{m}^{2}}{K(s)}\left(S R_{r} V_{s}^{2}\right)$

2- Second component is induction power, this power is always negative value.

$P_{i n 2}=-\frac{3 P(1-s) X_{m}^{2}}{K(s)}\left(R_{s} V_{r}^{2}\right)$

3- Third component is Synchronous power, this power is positive or negative

$P_{s y n}=-\frac{3 P(1-s) X_{m}^{2}}{K(s)} \frac{V_{s} V_{r}}{X_{m}}(D r \sin \alpha-D i \cos \alpha)$

Different component of power of DFIG can be further investigated after obtaining the total power of the used induction machine which is shown in Appendix. As shown in Fig. (2). Also the corresponding stator and rotor current are shown in Fig. (3).

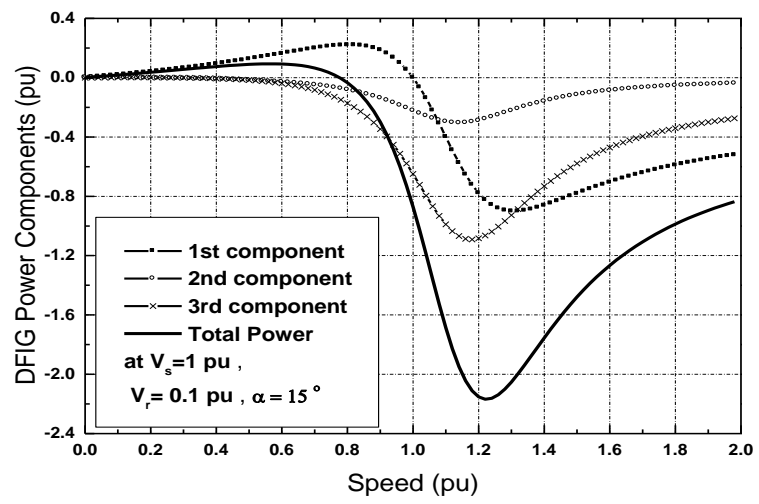

Fig. 2 Variation of the power component of DFIG with speed at $V_{s}=1 \mathrm{pu}, V_{r}=0.2 \mathrm{pu}$, and $\alpha=15^{\circ}$

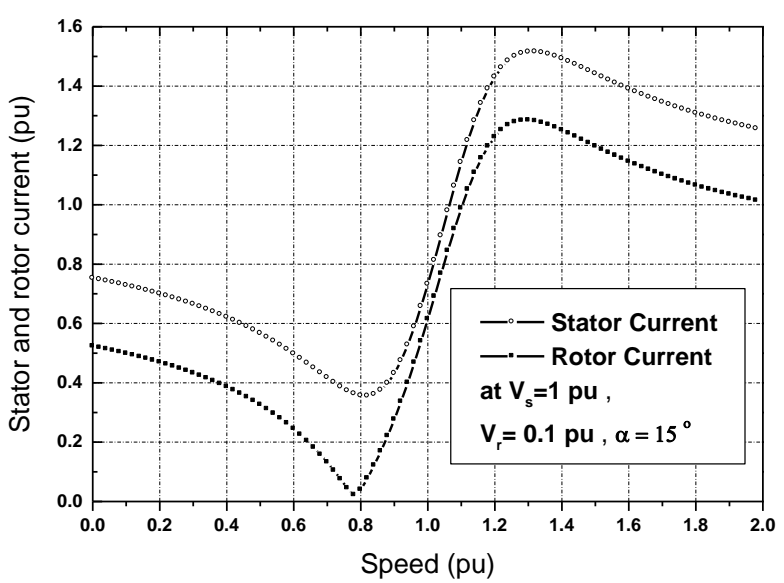

Fig. 3 Variation of the stator and rotor current of DFIG with at $V_{s}=1 \mathrm{pu}, V_{r}=0.2 u_{s}$ and $\alpha=15^{\circ}$

From Fig. (2), it is clear that the operation of DFIG at rated stator voltage will leads to higher motoring power $\left(1^{\text {st }}\right.$ component) at sub synchronous speed. Also from Fig. (3), it is obvious larger stator and rotor current than the rated values. These previous results will lead to un stability in machine operation.

\section{Steady State Performance Analysis of DFIG} The selection of the stator voltage, the rotor voltage magnitude and the rotor voltage angle affect on the DFIG steady state performance parameters, such as the total output power, the stator current, and the rotor current. This section investigates this effect using conventional technique. So extensive simulations work are done.

Three cases are considered:

(1) rotor speed and stator voltage are varied for a given constant value of rotor voltage magnitude and the rotor voltage angle;

(2) rotor speed and rotor voltage magnitude are varied for a given constant value of stator voltage and the rotor voltage angle;

(3) rotor speed and rotor voltage angle are varied for a given constant value of the stator voltage and rotor voltage magnitude .

\section{A. Effect of Rotor speed and stator voltage variation}

The rotor voltage magnitude is fixed at a value of $10 \%$ of rated stator voltage with zero Rotor voltage angle and stator voltage is varied from $1 \mathrm{pu}$ to $0.25 \mathrm{pu}$. So that for each value of stator voltage the rotor speed is increased gradually. 


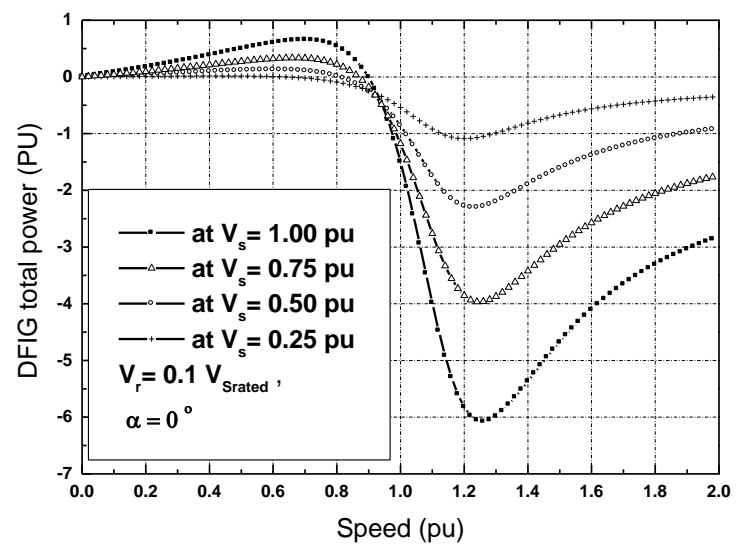

Fig. 4 Variation of the total power of DFIG with speed at different values of stator voltage

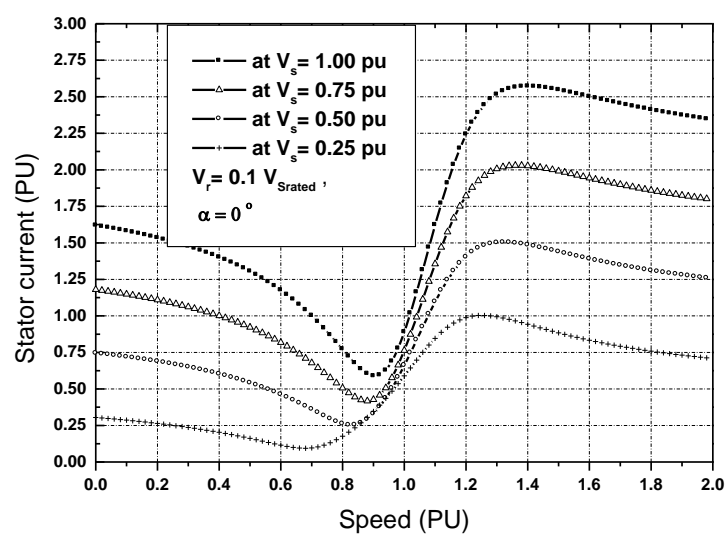

Fig. 5 Variation of the stator current of DFIG with speed at different values of stator voltage

From Fig. (4) and Fig. (5), it is noted that; the machine will be more stable for decreasing DFIG stator voltage. As lower motoring power (1st component) at sub synchronous speed. and lower stator current than the rated values have been got. So decreasing stator voltage is essential by putting

a transformer between the DFIG and the grid to step down the applied stator voltage on machine.

\section{B. Effect of Rotor speed and rotor voltage magnitude variation}

The stator voltage is fixed at a value of $0.5 \mathrm{pu}$, with fixed rotor voltage angle and rotor voltage is magnitude varied from $2.5 \%$ to $10 \%$ of rated stator voltage, so that for each value of rotor voltage is magnitude, the rotor speed is increased gradually.

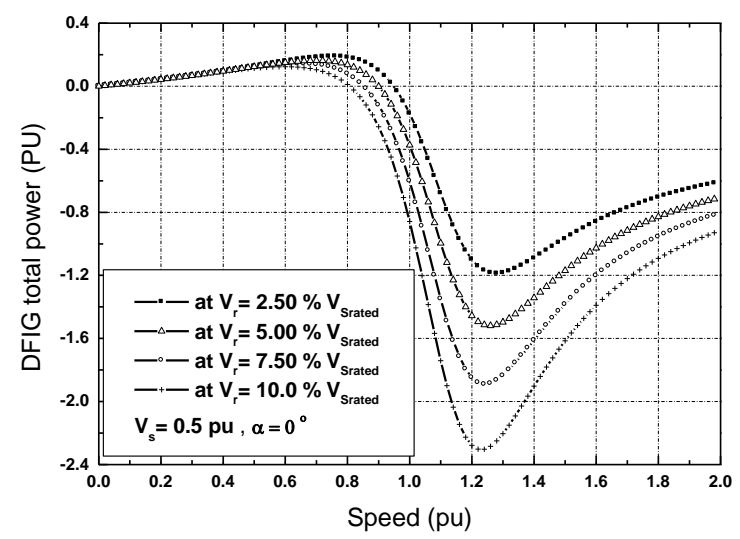

Fig. 6 Variation of the total power of DFIG with speed at different values of rotor voltage

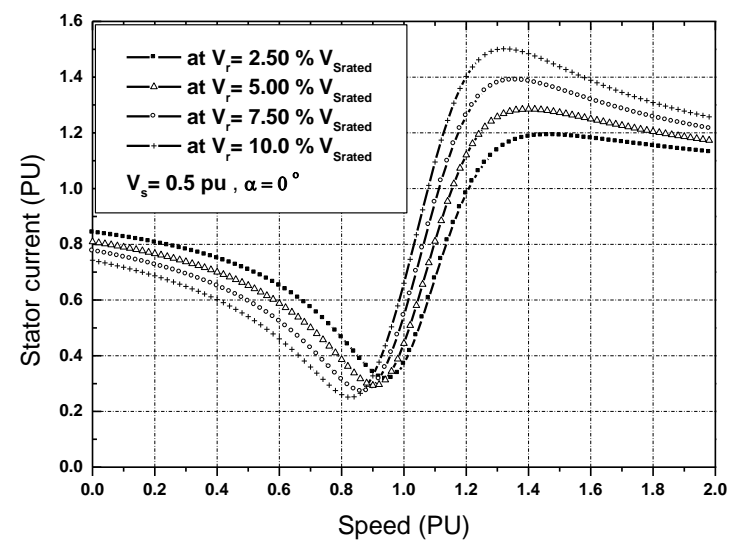

Fig. 7 Variation of the stator current of DFIG with speed at different values of rotor voltage.

Significant improvement in the generating power profile and the maximum power delivery capability of DFIG generator with higher rotor voltage as shown in Fig. (6). But the power profile improvement is accompanied by higher stator current with significant decreases in the operating region of the DFIG generator without overheating as shown in Fig. (7).

\section{Effect of Rotor speed and rotor voltage angle variation}

The stator voltage is fixed at a value of $0.5 \mathrm{pu}$, with fixed rotor voltage and rotor voltage angle is varied from -80 o to $80 \mathrm{o}$, so that for each value of load angle, the rotor speed is increased gradually. 


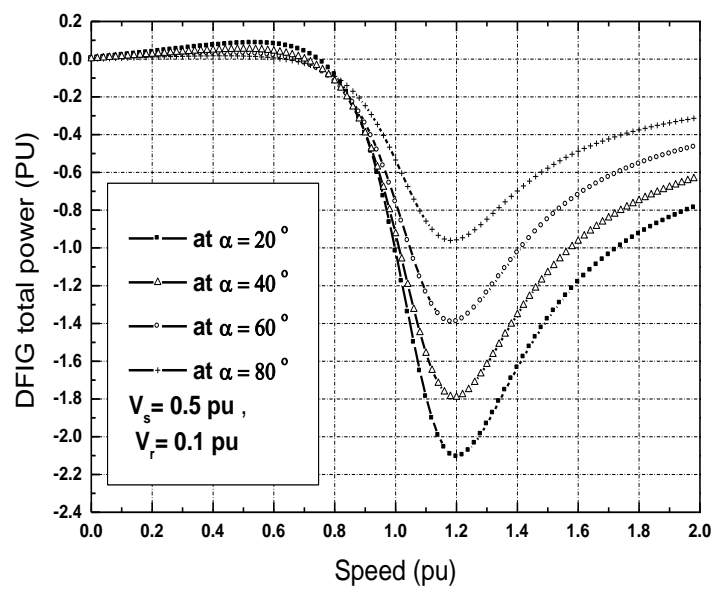

(a) Positive rotor voltage angle.

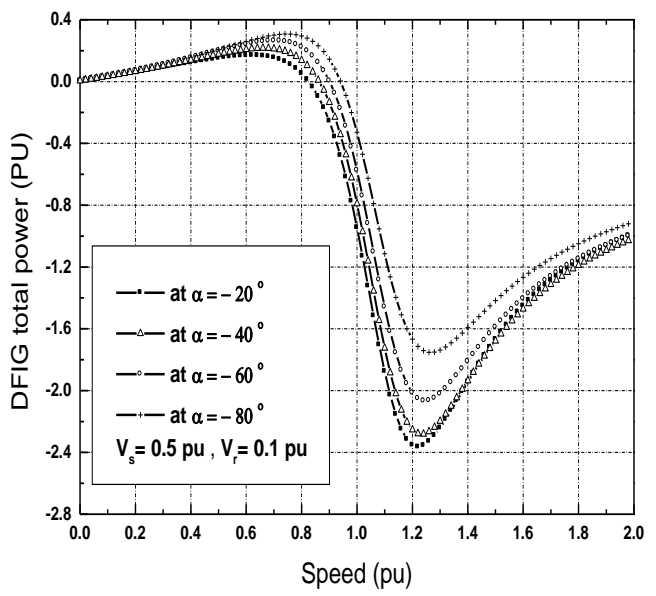

(b) Negative rotor voltage angle

Fig. 8 Variation of the total power of DFIG with speed at different values of rotor voltage angle.

Significant improvement in the maximum power delivery capability of DFIG generator with lower positive rotor voltage angle as shown in Fig. (8a). Where higher negative load angle

will

leads to higher motoring power at sub synchronous speed with slight decrease in maximum power delivery capability as shown in Fig. (8b). So the phasor relationship between the rotor voltage and stator voltage has great effect on the value and the type of DFIG power.

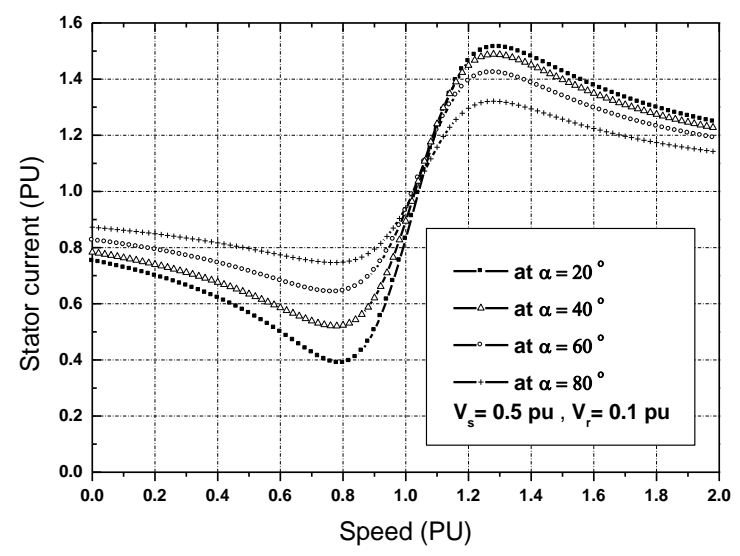

(a) Positive rotor voltage angle

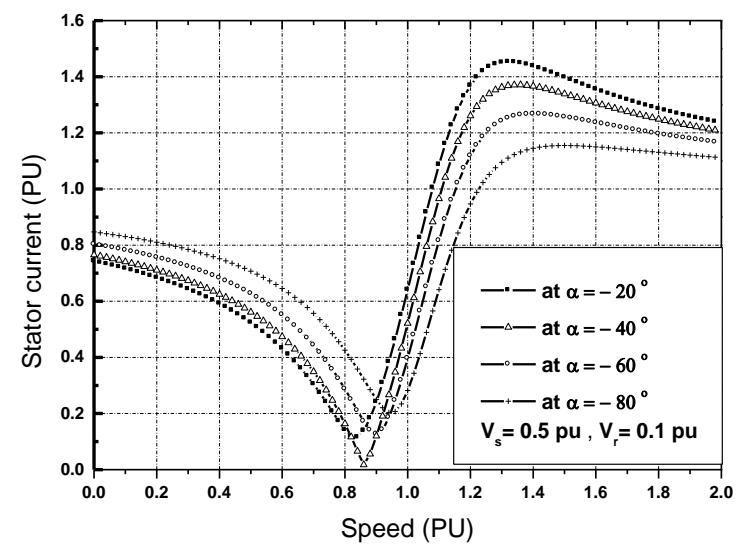

(b) Negative rotor voltage angle

Fig. 9 Variation of the stator current of DFIG with speed at different values of rotor voltage angle.

From Fig. (9), it is clear that for positive and negative rotor voltage angle; as the load angle increases, the stator current decreases. Significant improvement in the operating region of the DFIG generator without overheating with lower negative rotor voltage angle as shown in Fig. (9b).

\section{Analysis of DFIG Using ANFIS}

A class of adaptive multilayer feed forward networks with the capability of using past samples to forecast the sample ahead is known as ANFIS [18]. The applied learning method in these networks is Neural Network (NN) to tune the parameters of a Fuzzy Inference System (FIS). The neural network $(\mathrm{NN})$ back propagation provide adaptability, While the smoothness, is obtained due to the fuzzy controller (FC) interpolation [19]. 
The ANFIS network is based upon a first order TakagiSugeno model and is comprising of five layers.

One of FIS constraints is ANFIS has a single output, obtained using weighted average defuzzification [20]. So two ANFIS networks can be used for a two outputs: output power and stator current, working in parallel with the same inputs patterns.

In the first layer of the two models, the rotor speed $\mathrm{N}$, the rotor voltage magnitude $V_{r}$ and the rotor voltage angle $\square$, multiplied by respective weights, are each mapped through three fuzzy logic membership functions.

For ANFIS model has output power as an output, membership functions are chosen to be Triangle membership function for all the inputs where it is given a good outputs compared the others membership functions as shown in Fig. 9. With RMSE $=$ 0.0059144 or $29.57 \mathrm{~W}$.

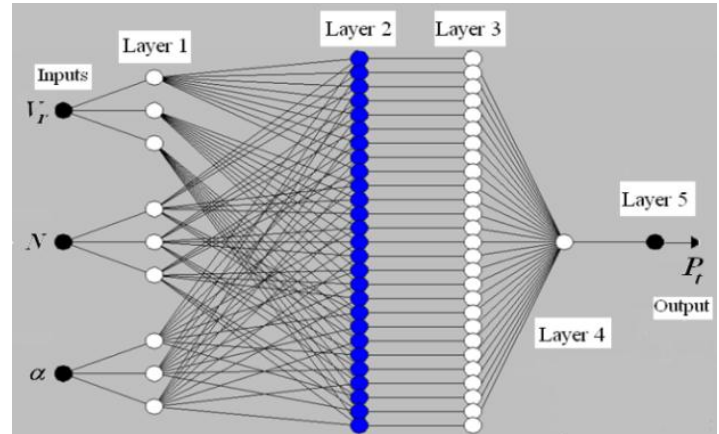

Fig. 10. Schematic diagram of the construction of the adopted output power ANFIS model

For ANFIS model has stator current as an output, membership functions are chosen to be Gaussian membership function for all the inputs where it is given a good outputs compared the others membership functions as shown in Fig. 10. With RMSE = 0.0046966 or $0.075 \mathrm{~A}$.

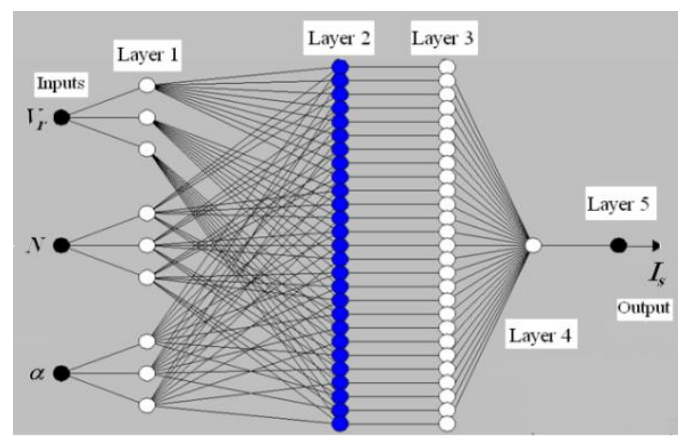

Fig. 11. Schematic diagram of the construction of the adopted stator current ANFIS model
In the second layer, the minimum error value of four input weights is calculated by rules firing strengths determination.

In the third layer, normalize the rules firing strengths. In the fourth layer, compute the contribution of each rule towards the overall output.

In the fifth layer, compute the overall output as the summation of contribution from each rule.

\section{RESULTS AND DISCUSSIONS}

The effect of the rotor voltage magnitude, the rotor speed, and the rotor voltage angle on the DFIG steady state performance characteristics can be investigated using ANFIS technique. So extensive simulations work are done.

Two cases are considered: (A) effect of rotor voltage magnitude on output power and stator current for a given constant value of rotor speed, and rotor voltage angle

(B) effect of rotor voltage angle on output power and stator current for a given constant value of rotor speed, and rotor voltage magnitude

A. Effect of rotor voltage magnitude variation

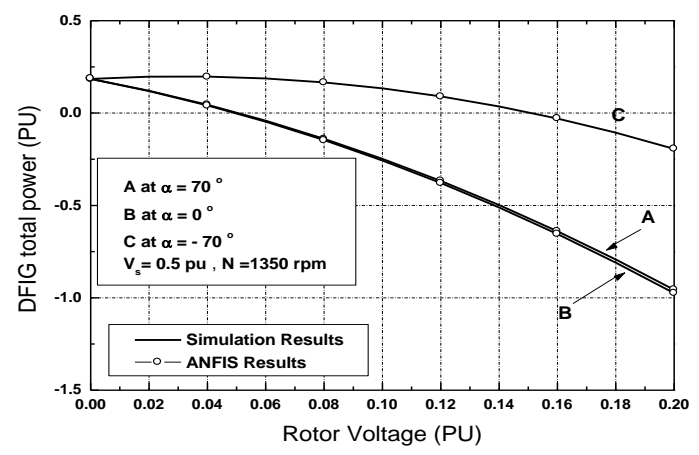

(a) At sub-synchronous speed.

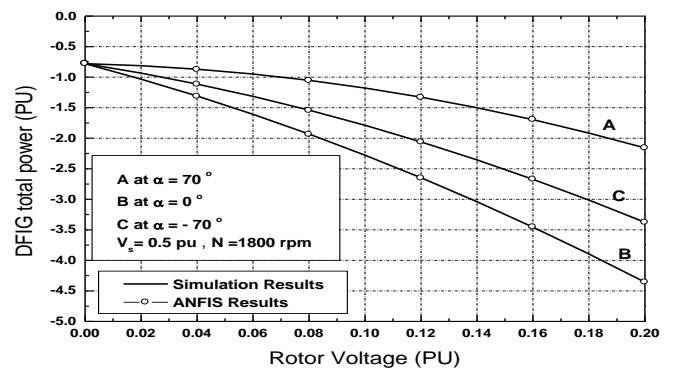

(b) At super-synchronous speed

Fig. 12 Variation of the total power of DFIG with rotor voltage at different values of rotor voltage angle. 


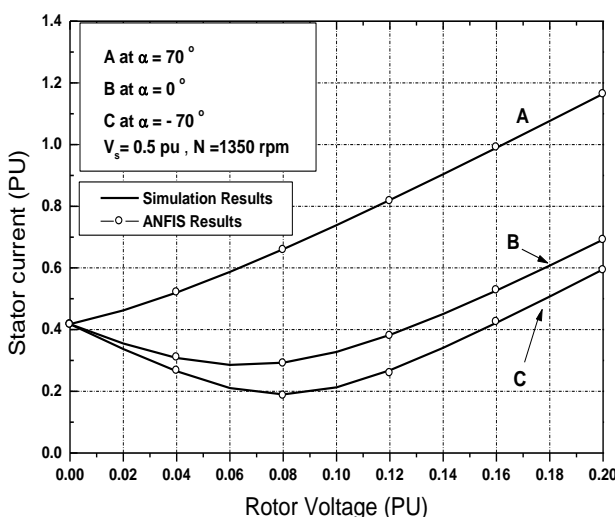

At sub-synchronous speed.

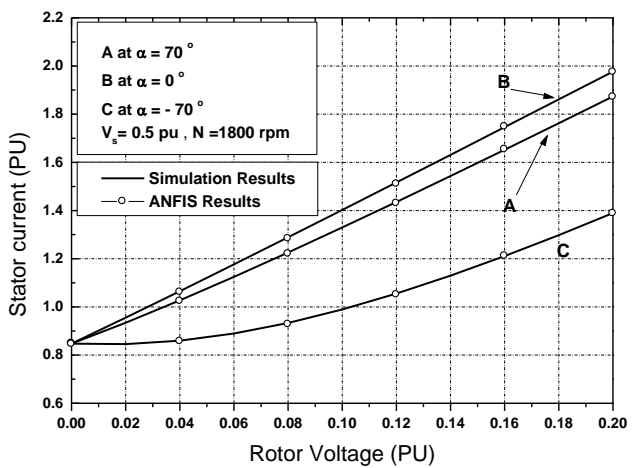

At super-synchronous speed

(b)

Fig. 13 Variation of the stator current of DFIG with rotor voltage at different values of rotor voltage angle.

\section{B. Effect of rotor voltage angle variation}

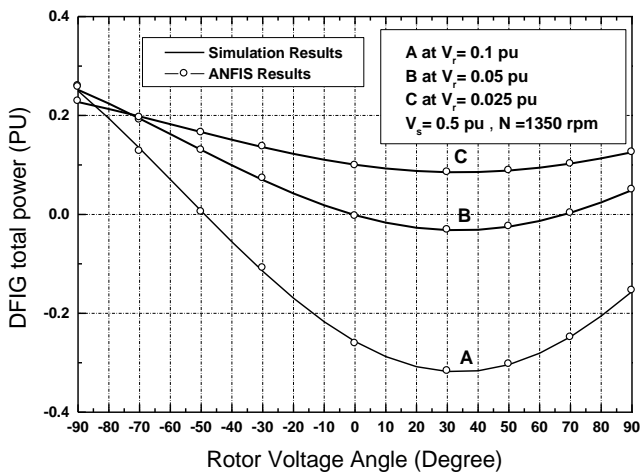

At sub-synchronous speed.

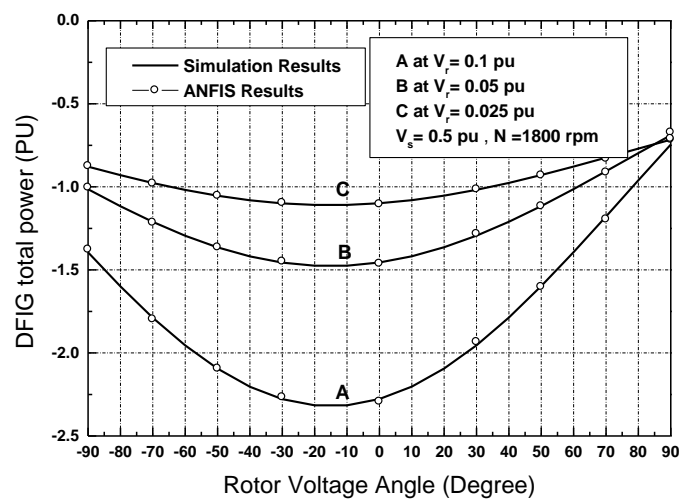

(b) At super-synchronous speed

Fig. 14 Variation of the total power of DFIG with rotor voltage angle at different values of rotor voltage.

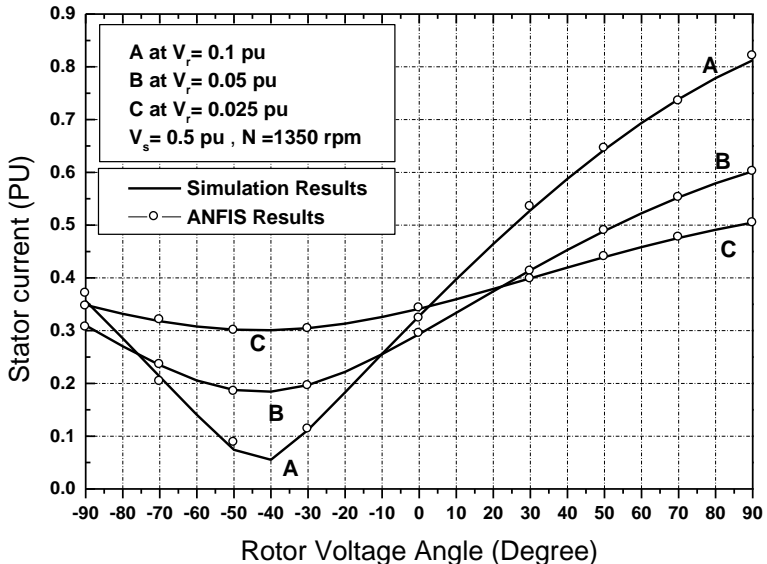

(a) At sub-synchronous speed.

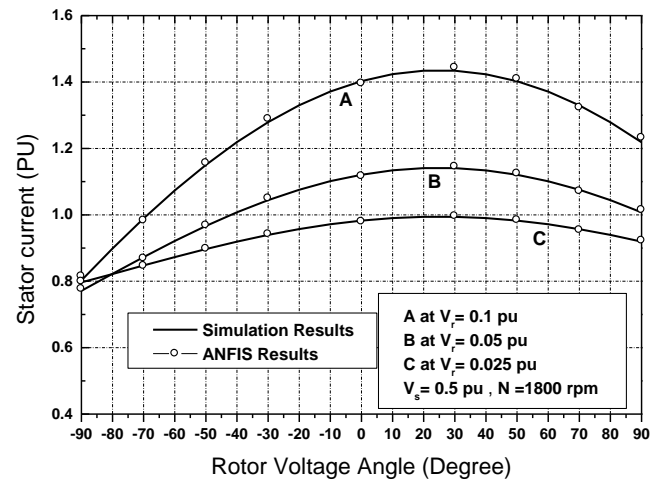

(b) At super-synchronous speed

Fig. 15 Variation of the stator current of DFIG with rotor voltage angle at different values of rotor voltage. 
Fig. 12, fig. 13, fig. 14 and fig. 14 depict a comparison between the estimated data by the conventional technique and ANFIS technique for DFIG output power and stator current.

It illustrates a very good agreement between data obtained by the conventional technique and ANFIS technique. So the ANFIS technique presents a better accuracy with short time without fatigued mathematical procedures.

\section{CONCOLUSION}

The steady state performance analysis of DFIG have been presented. The pre assessment process using different techniques to predict the effect of rotor voltage magnitude, rotor speed, and rotor voltage angle on output power and stator current of DFIG is the main contribution of this paper.

The computation of steady-state performance of DFIG using conventional technique has been found to be complex and take long time with fatigued mathematical procedures.

The application of an ANFIS technique for steady state analysis of DFIG has been demonstrated and has been found to be very effective for accounting the complex characteristics of this machine. ANFIS technique is superior in comparison to conventional analytical method as cleared in MSSE values. Further, no assumptions and complex computations are not requiring for ANFIS model.

It can be concluded that ANFIS model is worthy and beneficial towards accuracy and steady state analysis time than conventional technique.

\section{Appendix}

The generator under study is 3 -phase wound rotor, 5 $\mathrm{kW}, 380 \mathrm{~V}, 16 \mathrm{~A}, 50 \mathrm{~Hz}, 4$ pole [21], with below parameters:

$\mathrm{Rs}=4.55 \Omega, \mathrm{Rr}=1.546 \Omega, \mathrm{Ls}=4.14 \mathrm{mH}$,

$\mathrm{Lr}=2.7 \mathrm{mH}, \mathrm{Lm}=64 \mathrm{mH}$

Turns ratio (rotor to stator ), 1.257

\section{REFERENCES}

[1] R. J. Wai, W. H. Wang, and C. Y. Lin, "Highperformance stand-alone photovoltaic generation system," IEEE Trans. Ind. Electron., vol. 55,no. 1, pp. 240-250, Jan. 2008.

[2] M. H. Todorovic, L. Palma, and P. N. Enjeti, "Design of a wide input range DC-DC converter with a robust power control scheme suitable for fuel cell power conversion," IEEE Trans. Ind. Electron., vol. 55, no. 3,pp. 1247-1255, Mar. 2008.

[3] S. K. Kim, J. H. Jeon, C. H. Cho, J. B. Ahn, and S. H. Kwon, "Dynamic modeling and control of a grid- connected hybrid generation system with versatile power transfer," IEEE

Trans. Ind. Electron., vol. 55, no. 4,pp. 1677-1688, Apr. 2008.

[4] M. Cirrincione, M. Pucci, and G. Vitale, "A singlephase DG generation unit with shunt active power filter capability by adaptive neural filtering," IEEE Trans. Ind. Electron., vol. 55, no. 5, pp. 2093-2110, May 2008.

[5] R. Pena, J. C. Clare, and G. M. Asher, "Doubly fed induction generator using back-to-back PWM converters and its application to variable-speed windenergy generation,” Proc. Inst. Elect. Eng.-Elect. Power Appl. ,vol. 143, no. 3, pp. 231-241, May 1996. [6] F. Blaabjerg and F. Iov, "Wind power - A power source now enabled by power electronics," in Proc. Brazilian Power Electr. Conf., 2007, pp. 1-16.

[7] R. A. de Marchi, P. S. Dainez, F. J. V. Zuben, and E. Bim, " A Multilayer Perceptron Controller Applied to the Direct Power Control of a Doubly Fed Induction Generator," IEEE Trans. Sustain. Energy, vol. 5, no. 2, pp. 498-506, April 2014.

[8] X. Liu and X. Kong, " Nonlinear Model Predictive Control for DFIG-Based Wind Power Generation," IEEE Trans. Automation Science and Engineering, vol. PP, issue 99, pp. 1-10, Oct.2013.

[9] Huijuan Zhang, Shujun Cao, Shitao Wang, Fei Yu, " The Analysis of Steady-state Characteristics of Double Fed Induction Generator ", IEEE International Conference on Advanced Management Science (ICAMS), pp. 195-197, 9-11 July 2010. Chengdu, China.

[10] Yigong Zhang, Junchuan Jia, Weiguo Li, Dawei Wang, and Jin Liu, "Steady State Characteristic Analysis and Stability Assessment of Doubly Fed Induction Generator Based Wind Power Generation System", IEEE International Conference on Power System Technology (POWERCON), pp. 1-5, 24-28 Oct. 2010. Zhejiang, China.

[11] J. P. A. Vieira, M. V. A. Nunes, U. H. Bezerra, "Analysis Of Steady-State Operation Of DFIG-based Wind Turbines in Power Systems", IET Conference on Renewable Power Generation (RGP), pp. 1-5, 6-8 Sept. 2011. Edinburgh, UK

[12] A. M. Alkandari, S. A. Soliman, M. H. AbdelRahman, " Steady State Analysis of a Doubly Fed Induction Generator ", Scientific Research Journal on Energy and Power Engineering, vol. 3, no. 4, pp. 393 400, Sept. 2011.

[13] H. Sediki, Dj. Ould Abdeslam, T. Otmane-cherif, A. Bechouche, K. Mesbah, " Steady-State Analysis and 
Control of Double Feed Induction Motor ", World Academy of Science, Engineering and Technology, vol. 6, no. 1, pp. 153-161, Jan 2012.

[14] A. Gupta, S.N. Singh, D. K. Khatod, " Modeling and Simulation of Doubly Fed Induction Generator Coupled With Wind Turbine-An Overview", Journal of Engineering, Computers \& Applied Sciences

(JEC\&AS), Vol. 2, No. 8, pp. 45-54, August 2013

[15] Xiaobing Kong, Xiangjie Liu, Lee, K.Y., " Datadriven modelling of a doubly fed induction generator wind turbine system based on neural networks " IET

Renew. Power Gener., Vol. 8 , Issue. 8, pp. $849-857$, Nov. 2014.

[16] Menghal, P.M. and Laxmi, A.Jaya," Adaptive Neuro Fuzzy based dynamic simulation of induction motor drives"

IEEE International Conference on Fuzzy Systems

(FUZZ), 2013, Hyderabad, India

[17] A. Balogun, , O. Ojo, F. Okafor, and S. Karugaba, " Determination of Steady-State and Dynamic Control Laws of Doubly Fed Induction Generator Using Natural and Power Variables, " IEEE Trans. Ind. App., vol. 49, no. , pp. 1343-1357, May/June 2013.

[18] M. Darabian, A. Jalilvand, and R. Noroozian,

" Combined Use of Sensitivity Analysis and Hybrid Wavelet-PSO-ANFIS to Improve Dynamic Performance of DFIG-Based Wind Generation", Journal of Operation and Automation in Power Engineering, vol. 2, no.1 , pp. 60-73, Winter \& Spring 2014.

[19] P.G. Holmes and N.A. Elsonbaty, “ Cycloconvertor-excited divided-winding doubly-fed machines as a wind power convertor" IEE PROCEEDINGS, Vol. 131,Pt B, No.2 , pp. 61-69, March 1984.

\section{NOMENCLATURE}

$\begin{array}{ll}\boldsymbol{R}_{s}, \boldsymbol{R}_{r} & \text { Stator and Rotor resistances. } \\ \boldsymbol{L}_{\boldsymbol{m}} & \text { Magnetizing inductance. } \\ \boldsymbol{L}_{s}, \boldsymbol{L}_{r} & \text { Stator and Rotor leakage inductances. } \\ \boldsymbol{X}_{\boldsymbol{m}}, \boldsymbol{X}_{s}, \boldsymbol{X}_{r} & \text { Magnetizing, Stator and Rotor reactances. } \\ \boldsymbol{x}_{s}, \boldsymbol{x}_{r} & \text { Stator and Rotor leakage reactances. }\end{array}$

(1)

$\begin{array}{ll}\boldsymbol{\psi}_{s}, \boldsymbol{\psi}_{r} & \text { Stator and rotor fluxes. } \\ \boldsymbol{V}_{s}, \boldsymbol{V}_{r} & \text { Stator and rotor voltages. } \\ \boldsymbol{I}_{s}, \boldsymbol{I}_{r} & \text { Stator and rotor voltages } \\ \boldsymbol{\psi}_{s d q}, \boldsymbol{\psi}_{r d q} & \text { D and Q-axis stator and rotor fluxes } \\ \boldsymbol{V}_{s d q}, \boldsymbol{V}_{r d q} & \text { D and Q-axis stator and rotor voltages } \\ \boldsymbol{I}_{s d q}, \boldsymbol{I}_{r d q} & \text { D and Q-axis stator and rotor voltages } \\ \boldsymbol{\omega}_{s}, \boldsymbol{\omega}_{r} & \text { Stator and rotor angular frequencies } \\ \boldsymbol{P}_{t}, \boldsymbol{T} & \text { Total power and Developed torque } \\ \boldsymbol{P}_{i n \boldsymbol{l}} & \text { First induction power components. } \\ \boldsymbol{P}_{i n 2} & \text { Second induction power components. } \\ \boldsymbol{P}_{s y n} & \text { Synchronous power component. } \\ \boldsymbol{P} & \text { Number of pole pairs. } \\ \boldsymbol{n} & \text { Rotor Slip } \\ \boldsymbol{\alpha} & \end{array}$

$\boldsymbol{\psi}_{s}, \boldsymbol{\psi}_{r} \quad$ Stator and rotor fluxes.

$V_{s}, V_{r} \quad$ Stator and rotor voltages.

$\boldsymbol{I}_{s}, \boldsymbol{I}_{r} \quad$ Stator and rotor voltages

$\boldsymbol{\psi}_{s d q}, \boldsymbol{\psi}_{r d q} \quad \mathrm{D}$ and Q-axis stator and rotor fluxes

$\boldsymbol{V}_{s d q}, \boldsymbol{V}_{r d q} \quad \mathrm{D}$ and Q-axis stator and rotor voltages

$\boldsymbol{I}_{s d q}, \boldsymbol{I}_{r d q} \quad \mathrm{D}$ and Q-axis stator and rotor voltages

$\omega_{s}, \omega_{r} \quad$ Stator and rotor angular frequencies

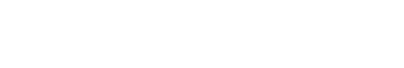

